\title{
The Occurrence of Conflicts and the Social Divide Do They Affect the Economic Growth of Sub-Saharan African Fragile Countries?
}

\author{
Yamben Michel Freddy Harry \\ Senior Lecturer Faculty of Economics and Management of the University of Macroura, Cameroon \\ Corresponding author: Yamben Michel Freddy Harry
}

Received: 04, April, 2021

Accepted: 12, April, 2021

Published: 01, May 2021

\begin{abstract}
The article is an empirical analysis of the relationship between social divide, the occurrence of conflict and economic growth. By examining the impact of the social divide and conflict on the economic growth of six countries in sub-Saharan Africa as well as the effects of predicted variables conflict and economic growth on the social divide, we use ARDL models from the econometric perspective to study the link between conflicts and growth then the Generalized Moments Method (GMM) to solve the endogeneity problem of our main variables and, this from dynamic panel data relating to the period 1980-2008. The results reveal that conflict destroys economic growth and conversely, economic growth creates new social divides that increase the opportunity for conflict and depress activity. The intensity of the conflicts in these countries seems to be able to project fragile economies more quickly on trajectories which lead them less towards their level of long-term equilibrium growth. Indeed, conflict assessment should be a central concern of development economists for the sake of economic recovery. Finally, the poor performance in terms of growth cannot be blamed on the conflicts whose exacerbation is the cause, but must lead decision-makers to reflect on the structural causes.
\end{abstract}

Keywords: Social divide, occurrence of conflicts, economic growth, fragile countries, non-stationary heterogeneity, Pooled Mean Group, Generalized Moments Method.

JEL Classification: 0110; 047; 055; F4

\section{Introduction}

The increase in inequalities, the decline in social indicators in terms of development, the predominance of dictatorial regimes incapable of transforming economic growth into an act of development, the evolution of very high GDP per capita in some countries which contrasts with their level of social development, the marginalization and exclusion of certain layers of the population as well as the bipolarization of societies between the rich on the one hand, and the poor on the other hand, seem today to systematically explain the evolution of social and armed conflicts forces as well as the chaining of conflict factors in certain subSaharan countries (Yamben and Tenlep, 2021, Chan et al. 2019, Venugopal, 2018, Triellet, 2018, World Bank, 2016, Paugam, 2016-2014). Indeed, disadvantaged populations are often forced to rebel against the legitimate state, through rebellions, insurgencies, civil wars or military coups (Bayramzadek, 2015, Fosu, 2015, Minoiu et al. 2014, Alesina, 2012, De Groot, 2010, Collier et al. 1999). This undermines social cohesion, the foundations of the state, and the overall productivity of factors of production and destroys any process of economic growth. However, the theoretical analyses of violence as well as social divide rest on two main foundations. On the one hand, we have utilitarian economic theories, in terms of the economic rationality of representative agents, and on the other hand, praxeologies, in terms of the adequacy of means for ends, favour factors internal to States by opposing the rulers and rebels (Kaldor, 1999). In this type of state, the economic structure is characterized by rents. So that their enrichment results more from the capture of wealth than from their creation, and this naturally feeds the chain of conflict factors (cultural, social, political, military, geopolitical) each having their own temporality anything that inhibits aggregate factor productivity and affects any growth target (IMF, 2019).

Thus, a country combining the most favourable conditions visà-vis the risks of the occurrence of war will have a risk of one in a million "chance" of facing a civil war, while this proportion is estimated at $99 \%$ for the one combining the most unfavourable conditions. As a result, instability becomes the rule and stability the exception (Grossman, 1991). This political instability and the resulting internal conflicts thus seem to have direct repercussions on economic performance. This has translated into periods of negative growth in average output per capita in these countries (World Bank, 2015, African development indicators, 2008). Indeed, the occurrence of these conflicts depends on the degree of intensity which can either lead to simple looting, destruction of infrastructure and natural resources (minor conflict) or to a 
fragmentation of the country into two or more poles, generally the north and the south of the country (major conflict) (IMF, 2008). Thus, the fragmentation of countries by rival groups leading to conflicts further exacerbates existing social disparities, compromising the livelihoods of vulnerable households within the same country. This climate of insecurity in the face of the rule undermines the productivity of economies and annihilates any development process and imposes on them "poor development" (Perroux, 1981).

However, conflicts, as well as social divide, constitute important factors in the destruction of economies in the sense that they weaken the economic fabric of the countries concerned during and after their occurrence. Indeed, in these fragile economies even when there is economic growth, social and economic inequalities and the concentration of capital by a ruling minority are amplified. Anything that creates new tensions and conflicts that generally benefit non-state groups, armed or not, and certain exogenous actors, more specifically multinational firms. Now, the absence of a rule of law capable of ensuring basic services and security for its citizens leads to a loss of legitimacy and a collapse of states, and therefore to a degradation of productivity and then to their internal and external competitiveness (Africa Policy and Economics Department, 2001). Thus, if it seems recognized, on both theoretical and empirical levels, that the social divide and the occurrence of armed conflicts influence economic growth, despite the debates on the significance of this impact, we can continue to question ourselves on the nature and intensity of conflicts and social fractures on economic growth. More specifically, by considering that the economic growth of a nation is its ability to sustainably improve the standard of living of its inhabitants and to provide them with a high level of employment and sustainable social cohesion, a guarantee of all economic development (Perroux, 1991), it would be relevant to analyse the nature and extent of the empirical relationship between the social divide, the occurrence of conflicts and economic growth. Contrary to what is done in the classic literature in terms of analysis of the social divide, conflicts and economic growth, the specificity of this work is to show that the social divide and conflicts annihilate economic growth in the short and long term and vice versa. So what is the nature of the empirical relationship between economic growth, social divide and conflict?

The rest of the article is organized as follows. The next section reviews the theoretical and empirical foundations on the relationship between the occurrence of conflict, social divide and economic growth. The second section describes the data and explains the empirical approach chosen. The results are discussed in section 3. while section 4 presents the conclusion and policy recommendations.

\section{Literature review}

\subsection{The specific weight of conflict factors and the occurrence of conflicts on economic growth}

The question arises as to what is the specific weight of economic factors and underdevelopment in the explanation of conflicts and in the process of spiralling and unregulated propagation that characterize them. War must be financed and may be motivated by the capture of wealth. Conflicts are fostered by economic underdevelopment, youth unemployment, poverty and the impossibility for states to perform sovereign security functions. Eighty per cent of LDCs have experienced conflict for 40 years, and the per capita income twice superior halves the risk of war (World Bank, 2003). In their theoretical model on which their empirical tests are based, Collier and Hoeffler (2000) place themselves within the utilitarian framework of Grossman (1991). They oppose rebellion, a form of organized crime characterized by greed, to the supposedly legitimate government and receiving grievance. "To get started, rebellion needs grievance, whereas to be sustained it needs greeds". The most significant variables are economic. Conflicts are all the more likely when the level of per capita income is low, the share of raw materials in exports is high, and the country is polarized around two large ethnic groups. These factors have since been refined and completed. The nature of the raw materials is central and the resources of the subsoil, in particular the hydrocarbons, are more factors of conflict than agricultural raw materials (Bannon, Collier, 2003). Questions of the credibility of powers and redistributive measures vis-à-vis excluded groups are central to explaining conflicts (Azam, 2000). Many studies devoted to Africa have sought to specify the economic factors of conflict (Annan, 1998; Elbadawi, Sambanes 2000; Hugon, 2003; Nour Abdel Lotif, 1999). According to the tests of Anyawu (2002), the main explanatory factors for African civil wars are the low rate of GDP growth, the importance of natural resources, the duration of peace, social fragmentation and the number of inhabitants.

However, while not all wars have an economic explanation, all need financing. African economies remain dominated by rents where enrichment results more from the capture of wealth than from their creation. The conflicts around the capture of rent involve a plurality of national, regional and international, private and public actors who cannot be reduced to only predatory rebels. They may stem from wastages by illegitimate governments or private international oligopolies. The guerrillas, rebels or lost soldiers, live on external support, predation on production or external aid or the capture of natural resources. The economies of closed wars financed with local resources differ from the economies of open war led by guerrillas benefiting from external financing and political or military-humanitarian sanctuaries (Jean Ruffin, 1996).

\subsubsection{Channels through which conflicts affect economic growth} The occurrence of conflicts affects economic growth because it increases political uncertainty, which in turn negatively affects key decisions of economic agents such as saving and investing. Therefore, a high probability of government change implies uncertainty about future public policies. This leads economic agents, averse to risk, to adopt a wait-and-see attitude by postponing or cancelling any initiative likely to increase the volume of economic activities. So this loss of confidence may, on the other hand, be more decisive for potential investors. Worse, such behaviour can only encourage the flight of local investors and the repulsion of foreign entrepreneurs, preferring to move towards more stable states. Anything that keeps investors reluctant, prevents foreign direct investment and the mobility of the capital factor, source of growth and accumulation of wealth (Adam Smith, 1776) and development of fragile economies (IMF, 2015). Asiedu (2004) argues that African countries are perceived as inherently risky, which does not favour the inflows of foreign direct investment. Investors are concerned about the risks associated with the likelihood of adverse changes. This suggests that the risks are perceived to be higher for countries in sub-Saharan Africa than in other regions (Bhattacharya et al., 1997). Thus, conflicts affect economic outcomes primarily through the destruction of human and physical capital, changes in public spending and private investment, as well as the disruption of economic activities and social life (Blattman and Miguel, 2010). However, the specific 
impacts depend on the unique characteristics of each conflict. Indeed, it is not only the type of conflict, but also its intensity, duration and geographic distribution that depress activity and reinforce the economic consequences.

Collier (2009) establishes an essentially negative link between the duration of the civil war and economic growth. His approach, however, is criticized for ignoring variations in the scale and scope of conflicts. Imai and Weinstein (2000) stress the importance of the geographic distribution of conflicts and conclude that widespread civil wars affect economic growth five times more than conflicts in small parts of the country. Bodea and Elbadawi (2008) distinguish different levels of political violence and find particularly negative growth impacts for civil wars, compared to less severe effects resulting from riots or military coups. Likewise, Koubi (2005) finds that the impact of civil war on long-term economic growth is proportional to the severity of conflicts in terms of conflict-related human losses. Abadie and Gardeazabal (2003) show a negative impact of the ETA terrorist conflict on economic growth in the Basque Country. Depending on the intensity of terrorism, Basque GDP per capita has fallen, on average, by 10 percentage points compared to other Spanish regions. Lopez and Wodon (2005) used time series data to estimate the impact of the 1994 genocide on the evolution of Rwanda's GDP per capita. Based on the detection and correction of outliers, their results indicate a significant loss of GDP in the short term, although no impact is found on postgenocide growth rates. Cerra and Saxena (2008), for example, show that the initial economic decline in countries affected by civil war is substantial, but they predict at least partial recovery in production levels after a relatively short period. Contrary to the convergence forecasts of neoclassical growth models where the full level of catching up to pre-war levels in the post-conflict period is not observed. Using different data and methodologies, De Groot (2010) confirms the negative economic effects of violent conflict for direct neighbours, but finds positive spill overs for noncontiguous areas. The overall negative effects of violent conflict on economic development are therefore well documented and appear to be shaped by the type, duration and geographic distribution of conflict. However, our understanding, and especially empirical evidence, of the mechanisms by which conflict is transmitted to growth remains limited. In the following, we characterize the drivers of economic downturn in conflicting societies and present the existing evidence on the various effects of conflict in economic activities.

First, the level and rate of growth of the capital stock are negatively affected by conflict damage through the prism of reduced investment. The destruction or dislocation of production facilities and key infrastructure, especially in the areas of transport, communication and energy, hamper economic activity. Private agents become involved in portfolio withdrawal and substitution as perceived risk increases and investments in areas unaffected by violent conflict offer higher relative returns with lower risk. Government spending on productive activities is expected to decline due to the imposition of the tax base and obstruction of tax administration, on the one hand, and the diversion of public funds to military and security spending on the other hand. Bad macroeconomic policy, with rising budget deficits and rising inflation, tends to further hamper economic growth. Svensson (1998), for example, identifies a potential channel from political instability and weak property rights associated with reduced private investment. A negative impact of political violence on private savings and domestic investment is also found by Fielding (2004) in his analyses of the macroeconomic impacts of the Israeli Intifada. Gupta et al. (2004) reveal the detrimental effects of armed conflict on tax revenue and public investment: increased government spending on defence is associated with macroeconomic instability and the diversion of resources from socially and economically productive sectors. Knight et al. (1996) relate this delaying impact of growth in military spending to negative effects on capital formation and resource allocation.

In addition, Collier and Hoeffler (2004) insist on an explanation from the point of view of the labour market: they hypothesize that low income implies unemployed youth for whom the opportunity cost of joining a rebel group is low. In contrast, Fearon and Latin (2003) emphasize an explanation relating to state capacity. According to this approach, per capita income is largely a proxy variable for the administrative, military and police competence of the state, and therefore the ability to deter or contain emerging insurgencies. The explanation using state capabilities is probably the most compatible with the lack of a robust intra-country relationship between income and civil war. One might not expect a rigid relationship between state capacity and income, as short-term changes in income are expected to affect labour market conditions. The explanation by the labour market would be more compatible with the analysis of Miguel, Satyanath and Sergenti (2004) who show that an exogenous variation in rainfall is correlated with the outbreak of the civil war in sub-Saharan Africa. They argue that it is possible to identify a direct causal effect of income on the propensity to civil war by using the variation in income associated with that of precipitation, under the assumption that the variation in precipitation cannot affect the propensity to civil war uniquely through income. As they find, it is possible that heavy rainfall could negatively impact state capacity by making roads less passable. Finally, Imai and Weinstein (2000) conclude that reductions in private investment affect economic growth much more than slowdowns in public investment.

In this triangle, the link between the social divide, the occurrence of conflicts and growth is essential but controversial. The analysis of the evolution of the growth rate of the real gross domestic product (GDP) and the variable occurrence of conflicts over the last 40 years suggests a negative correlation between social divide and the political turbulences that have occurred during this period as well as economic growth, as evidenced by statistics from the World Bank (2014). Stiglitz and Bilmes (2008), show that the social divide and the occurrence of conflicts have a negative and significant impact on economic growth in developing countries. In the sense that civil conflicts undermine the institutional quality via the absence of State control over part of the national territory, through the establishment of exceptional regimes and via the absence of consensus in the taking of decisions. Some point fingers at the dependence of African countries on developed countries. The colonial legacy argument holds that developing countries have bad institutions because it is the legacy left by European settlers. Others, on the other hand, blame poor macroeconomic policy as well as inequalities in human development and labour markets (Fosu, 2015). However, (Verporten, 2013) suggests that it is difficult to have a clear opinion on the impact of social divide and conflict on economic growth. Given that Rwanda has succeeded in combining rapid growth of around 5\% per year, reduction in inequalities (Gini coefficient of 0.52 in 2005 and 0.49 in 20010/11) and reduction in poverty (numerical index falling from 0.58 to 0.45 ) after the genocide. The specificity of this analysis is that the same factors that seem to explain, for example, low inequality could lead to higher growth (Psacharopoulos et al. 2018). And conversely, growth can create and polarize new forms of social fractures and 
reinforce the misery of populations, especially in unstructured economies such as those of developing countries (Triellet, 2018).

\section{The debate over the long-term effects of armed conflict on economic growth}

African wars are essential factors in the decomposition of states and economic underdevelopment, not only because of the destruction of people or property they cause, but because of the insecurity in which economic agents find themselves. They lead to the generalization of migrations and refugees. They participate in the proliferation of diseases such as AIDS; they weaken property rights or restrict access to basic social services. Thus, the traps of conflict and underdevelopment are self-sustaining. In a globalized world, one cannot assume that the withdrawal of the former colonial powers leaves the field open to an African history disconnected from world time. Wars are equally an indication of the business and customer systems that binds Africa to the outside world, sometimes in mafia-type relationships.

\subsection{Channels through which the social divide affects economic growth}

According to classical theory, income inequality is a prerequisite for growth, because the rich are characterized by a marginal propensity to save, which is greater than that of the poor. For the same level of aggregate income, an unequal distribution of income will therefore generate a greater total flow of savings, which will promote investment and growth (Kaldor, 1956). According to Kuznets' theory, in the early stages of development, growth exacerbates inequalities in the distribution of income up to a certain threshold of per capita income, and then attenuates them beyond that threshold. This theory has been rejected on the evidence base. There is no clear link between the current episode of growth in sub-Saharan Africa and an increase in income inequality as one would expect in low-income countries if Kuznets' theory had held true. Traditional growth theory establishes a direct relationship between economic growth and the social divide. The first thesis, developed by Kuznets (1955), indicates that the relationship between GDP / capita and inequality is in the form of an inverted U. Hence the following questions: Does income inequality weigh on economic growth? What is the correlation between inequalities and growth? Kuznets (1955) assumed that there is only one type of relationship between income inequality and GDP growth.

Based on the analysis of the historical evolution of inequalities during the industrialization of Germany and the United Kingdom during the first half of the 20th century, Kuznets proposes a general law which determines the link between growth and inequalities under the shape of an inverted U-curve where on the $\mathrm{x}$-axis is the GDP per capita and on the y-axis are the inequalities expressed by the GINI coefficient. According to Kuznets this curve reflects the weakness of the GDP during the first phases of development. At the same time, inequalities further increase until the country reaches a certain level of development. From a certain threshold of development, inequalities stabilize, and then decrease. In contrast, the new and more modern political economy of development strongly asserts that widening income inequalities can slow growth through various transmission mechanisms, for example by spreading political and social instability and then reducing productivity gains.

In the same vein, Dubois (2005) explains that the increase in inequalities appears with growth because both very poor and very rich countries have relatively egalitarian income structures. The transition from one situation to another implies first an increase in inequalities and later a decrease in them. We also observe that economic growth does not act in the same way on inequalities due to differences in income level. In poor countries, growth increases inequalities while it reduces them in high-income countries. This that explains why in poor countries the poor are poorer and the richer are richer. Indeed, these theories present the impact of inequalities on growth, showing that by hampering the accumulation of human capital, income inequalities compromise the possibilities for disadvantaged populations to be educated, thus limiting social mobility, skills development and productivity (Chen et al. 2016). Thus, high initial inequalities can erode the ability of growth to reduce poverty and therefore fuel the occurrence of conflict (Adams (2004). Blattman and Annan (2007), also show that young men who have been recruited into armed groups have received less education, and are less likely to have a skilled job, and also earn lower wages. (Yotopoulos, 1966) argues that political instability and underdevelopment in southern countries would be the consequence of historical processes put in place by the countries of the North resulting in the economic dependence of the countries of the South. In contrast, the new and more modern political economy of development strongly asserts that widening income inequalities can slow growth through various transmission mechanisms, for example by spreading political and social instability, unproductive rent-seeking activities and the growing precariousness of property rights. McMillan et al. (2014) observed that, over the period 1990-2005 at least, the structural change operated by African economies has generally weighed on growth in the countries in their sample. On average, the labour force has shifted from highly productive activities to low productive activities, which seems to confirm that most of the labour force leaving agriculture is found employed in activities whose level productivity is even lower, mainly in the informal sector where wages are derisory (Deverajan, 2013). Thus, a low per capita income is strongly correlated with the outbreak of the civil war, insofar as it is a proxy variable of the capacity of the central power to dissuade and repress armed detractors, as well as of its capacity to provide public services.

\section{Section Two: Estimation Strategy and Data}

We draw on Mankiw et al. (1992) from the theoretical point of view, and ARDL models from the econometric point of view to first study the link between conflicts and growth and then secondly, inequalities and growth through a GMM due to the endogeneity of certain variables. However, the theoretical transmission channel through which the impact of conflicts passes is done globally via parameter A. In this model, the postulate of exogenous technical progress can be replaced by an endogenous knowledge growth model by admitting that the accumulation of human capital has a dynamic similar to that of physical capital. It is a derivative of the following Cobb-Douglas type production function:

$$
Y(t)=K(t)^{\alpha} H(t)^{\beta}[A(t) L(t)]^{1-\alpha-\beta}
$$

Where, $\boldsymbol{\alpha}$ and $\boldsymbol{\beta} \in[0,1]$ and $\boldsymbol{t}$, the time.

This implies that the production function is at constant returns to scale relative to its three factors which are physical capital (K), human capital $(\mathrm{H})$ and productivity-augmented labour (AL). When 
we consider a large enough number of individuals and a large number of years, equation [1] takes on a more elaborate form and its estimation is subject to dynamic panel estimation methods. The initial specification of the model used conforms to the standard neoclassical growth model. It mainly takes into account the fundamental determinants of the stationary state, which are the accumulation of physical capital, population growth and a factor of convergence. For the purposes of our analysis of the link between conflict and social divide, we introduce military spending, political system, the status of the chief of executive, human capital and a set of macroeconomic variables, so that the growth equation can be formulated as follows:

$$
\ln y_{i t}=\theta_{0 i}+\theta_{1 i} \ln k_{i t}+\theta_{2 i} \ln h_{i t}-\theta_{3 i} n_{i t}-\theta_{4 i} g_{i t}+\sum_{j=4}^{m} \theta_{j i} V_{i t}^{j}+\theta_{m+1, i} t+\mu_{i t}
$$

$\mathrm{i}=1,2, \ldots, \mathrm{N}$ and $\mathrm{t}=1,2, \ldots, \mathrm{T}$.

where $y_{i t}$ corresponds to economic growth measured by the overall productivity of production factors including the ratio of GDP to the stock of capital, $k_{i t}$ to the stock of physical capital, $h_{i t}$ to human capital ${ }^{1}, n_{i t}$ the instrumented conflict variable of the model takes three modalities: the first zero ( 0 ) refers to the absence of the conflict, the second (1) when the conflict is minor, and the third (2) when it is major, $g_{i t}$ the instrumented inequality variable of the model takes three modalities: the first zero (0) returns to the absence of inequality, the second (1) when the inequality is less pronounced, and the third (2) when it is very pronounced, $V_{i t}^{i}$ to the vector of variables that influence the overall productivity of production factors. The variable $t$ represents a time trend. Equation [2] will be estimated with and without the time trend. We assume that all the variables in equation [2] are $I(1)$ and co-integrated. Moreover, the error term is a process $I(0)$ for all $i$ and is independently distributed through $t$. These characteristics imply an error correction model in which the short-term dynamics of variables in the system are influenced by the derivation from equilibrium as suggested by Bassanini and Scarpetta (2001), the diagnostic tests of Country-specific regressions behave better when only one lag per variable is kept. Therefore, we assume that the maximum fixed offset of each variable is one, resulting in an autoregressive process. Thus, the autoregressive distributed lag model, ARDL (p, q, q..., q) which makes it possible to reduce to a stable growth in the medium term with adjustments is:

$$
\begin{aligned}
\ln y_{i t}= & \lambda_{1 i} \ln y_{i, t-1}+\delta_{10 i} \ln k_{i t}+\delta_{11 i} \ln k_{i, t-1}+\delta_{20 i} \ln h_{i t}+\delta_{21 i} \ln h_{i, t-1}-\left(\delta_{30 i} n_{i t}+\delta_{31 i} n_{i, t-1}\right) \\
& +\sum_{j=4}^{m}\left[\delta_{m 0 i} V_{i t}^{j}+\delta_{m 1 i} V_{i, t-1}^{j}\right]+\delta_{(m+1) 0 i} t+\mu_{i t}+\varepsilon_{i t}
\end{aligned}
$$

Therefore, equations [2] and [3] can be set in the error correction equation as follows:

$$
\begin{aligned}
\Delta \ln y_{i t}=\phi_{i} & {\left[\ln y_{i, t-1}-\theta_{0 i}-\theta_{1 i} \ln k_{i t}-\theta_{2 i} \ln h_{i t}+\theta_{3 i} n_{i t}-\sum_{j=4}^{m} \boldsymbol{\theta}_{j i} V_{i t}^{j}-\boldsymbol{\theta}_{m+1, i t}\right] } \\
& -\delta_{11 i} \Delta \ln k_{i t}-\delta_{21 i} \Delta \ln h_{i t}+\delta_{31 i} \Delta n_{i t}-\sum_{j=4}^{m} \delta_{m 1 i} \Delta V_{i t}^{j}+\boldsymbol{\varepsilon}_{i t}
\end{aligned}
$$

Where the convergence parameter $\phi_{i}=1-\lambda_{i}$ and the parameters which influence the path of production per capita at a stationary state are:

$$
\boldsymbol{\theta}_{0 i}=\frac{\boldsymbol{\mu}_{i t}}{\boldsymbol{\phi}_{i}} ; \boldsymbol{\theta}_{1 i}=\frac{\boldsymbol{\delta}_{10 i}+\boldsymbol{\delta}_{11 i}}{\boldsymbol{\phi}_{i}} ; \boldsymbol{\theta}_{2 i}=\frac{\boldsymbol{\delta}_{20 i}+\boldsymbol{\delta}_{21 i}}{\boldsymbol{\phi}_{i}} ; \boldsymbol{\theta}_{3 i}=\frac{\boldsymbol{\delta}_{30 i}+\boldsymbol{\delta}_{31 i}}{\boldsymbol{\phi}_{i}} ; \boldsymbol{\theta}_{4 i}=\frac{\boldsymbol{\delta}_{40 i}+\boldsymbol{\delta}_{41 i}}{\boldsymbol{\phi}_{i}} ; \boldsymbol{\theta}_{5 i}=\frac{\boldsymbol{\delta}_{50 i}+\boldsymbol{\delta}_{51 i}}{\boldsymbol{\phi}_{i}}
$$

However, the so-called "Pooled Mean Group" (PMG) estimator is usually preferred because it constitutes an intermediate solution between the condition of homogeneity of all the slope coefficients imposed by the DFE estimator and the absence of restrictions that postulates the so-called "Mean Group" (MG) estimator. Indeed, the PMG estimator allows variations from one country to another from the coordinates to the intercept, of the convergence parameter, of the short-term coefficients and of the error variances, although it imposes the homogeneity of long-term parameters (OECD, 2001).

\subsection{Power and exogeneity test of instruments}

Before estimating the model, methodological precautions guaranteeing the validity of the results from the estimations of the diagnostic tests of the residues, endogeneity as well as exogeneity of the instruments were carried out since just a partial violation would weaken the validity of the numerical values obtained. To analyse the reverse causality, we predict the growth of per capita GDP and the occurrence of conflicts which we include in equation [10]. The reason is that the same factors that seem to explain low inequality could lead to higher growth (Barro and Lee, 2011) and vice versa. Our specification follows that of Goderis and Malone (2009) and is completed by macroeconomic level inequality equations (Deininger and Squire, 1997) including a system of simultaneous equations: 


$$
\begin{aligned}
& y_{1 i j t}=z_{1 i j t} \delta_{1}+\varepsilon_{1 i j t} \\
& g_{2 i t}=g_{2 i t-1} \delta_{21}+\alpha_{2} y_{1 i t}+z_{2 i t} \delta_{22}+\mu_{i}+\varepsilon_{2 i t} \\
& n_{3 i t}=n_{3 i t-1} \delta_{31}+\alpha_{3} y_{1 i t}+z_{3 i t} \delta_{32}+v_{i}+\varepsilon_{3 i t}
\end{aligned}
$$

where [5] represents GDP per capita growth. It is in reduced form. [6] and [7] represent the social divide and conflict equations. They are in structural form. Indeed, growth is potentially endogenous in equations [6] and [7]. $y_{1 i j t}, g_{2 i t}$ and $g_{2 i t-1}$ represent respectively the GDP and the Gini inequality and the lagged variable of the Gini inequality. Whereas $n_{3 i t}$ and $n_{3 i t-1}$ represent the conflict and the lagged variable of the conflict. $z_{1 i j t}, z_{2 i t}$ and $z_{3 i t}$ represent the respective vectors of the explanatory variables of $y_{1 i j t}, g_{2 i t}$ and $n_{3 i t} \delta_{1} ; \delta_{21} ; \delta_{22}$ and $\alpha_{2}$ represent the unknown parameters associated with the vectors of the respective explanatory variables of $y_{1 i j t}$ and $g_{2 i t}$. Likewise, $\varepsilon_{1 i j t}$ and $\varepsilon_{2 i t}$ represent the respective error terms of $y_{1 i j t}$ and $g_{2 i t} . \mu_{i}$ is the country fixed effect. Estimation of the specified model requires determining the reduced form of equations [6] and [7] of the model. Thus, we substitute $y_{1 i j t}$ in $g_{2 i t}$ and $n_{3 i t}$ and obtain firstly, the reduced form of $g_{2 i t}$ and secondly, the reduced form of $n_{3 i t}$. The procedure for estimating the specified model consists of two steps. The first step is to determine $\hat{\delta}_{1}$ who represents the estimated value of the parameter $\delta_{1}$. The second stage of the estimation aims to determine the estimated values of the structural parameters; $\delta_{21} ; \delta_{22}, \alpha_{2}, \delta_{31}, \alpha_{3}, \delta_{32}$ of equations [6] and [7] of the previous original model. Thus, given the estimated values $\hat{\delta}_{1}$ determined in the previous step, the variables $z_{1 i j t} \hat{\delta}_{1}$ are constituted. We then obtain $\hat{\delta}_{21}, \hat{\delta}_{22}, \hat{\alpha}_{2}, \hat{\delta}_{31} \hat{\delta}_{32}$ et $\hat{\alpha}_{3}$ and from the regression by the method of generalized moments $(\mathrm{GMM})$ of $g_{2 i t} \eta_{3 i t}$ respectively on $g_{2 i t-1}, n_{3 i t-1}, z_{2 i t}, z_{3 i t}$ and $z_{1 i j t} \hat{\delta}_{1}$ (and not on $\left.y_{1 i j t}\right)$.

\subsection{Nonlinear Equation and Generalized Moments Method (GMM) of Arellano and Bond (1991)}

The dependent variable of the model equation is social divide. Growth and the occurrence of conflicts have both non-linear and endogenous effects. This comforts our position by using a GMM which allows the purging of those elements of bias and endogeneity of the model which are likely to undermine the recommendations of economic policies. Hence this choice and this following specification:

$$
\ln g_{2 i t}=\ln g_{2 i t-1}+X_{i t}+\hat{Y}_{i t}+\hat{N}_{i t}+\mu_{i}+\varepsilon_{i t}
$$

$\ln g_{2 i t}, \ln g_{2 i t-1}$ represent respectively the logarithm of Gini and its lagged variable. $X_{i t}$ is the matrix of control variables. $\hat{Y}_{i t}$ is the predicted variable of growth. It is determined after estimating equation [1] of our system of simultaneous equations with economic growth as its dependent variable. $\hat{N}_{i t}$ is the predicted variable of conflict. The two predictors namely, $\hat{Y}_{i t}, \hat{N}_{i t}$ are instrumented in the specified model equation $[8], \mu_{i}$ the country fixed effect and $\varepsilon_{i t}$ the error term. When specifying this type of equation, a specification problem is usually observed. We use an estimator derived from the generalized method of moments (GMM) which is more efficient than the traditional double least squares (DMC) method.

\subsection{Data}

The study is carried out on a sample of panel data from six countries relative to the period 1980-2008. These countries have the particularity of having experienced internal conflicts and even major social fractures over relatively long periods. The dependent variable is economic growth measured by GDP. The data used come from the Milanovic database (2005). It merges three different databases: that of Deininger and Squire (1997), that of the United Nations (WIDER) and the World Income Distribution (WID) database. Social divide is reduced to the Gini coefficient and comes from data from the World Bank (2016) and databases. In order to examine the differences between the calculation methods from one database to another or from one year to another, we introduce into all our estimates three dummy variables capturing whether the Gini coefficient has been calculated at from consumption of income in real or nominal terms. Variables of interest: occurrence of conflicts (the occurrence of conflicts which describes the years during which the country experiences a situation of internal conflicts and the intensity of conflicts which describes in the event of conflicts during a given year). Also, we distinguish: a minor intensity in case of minor internal conflicts and a major intensity in the presence of a real war. The conflict variable is determined by the military status of the chief executive (this variable is dichotomous and takes the value 1 if the chief executive is a military person when he takes power and governs; it takes the value 0 if the chief executive is chief executive is a civilian or was in treaty or formally withdrawn from his military attributes before assuming power); the political system is polytomous and takes the values 1 if the system is presidential, 2 if the system is Assembly-elected President and 3 if the system is parliamentary. The number of years in power of the chief executive and the plurality of the system which takes the values 1 if the system is pluralistic and 0 otherwise. Military spending, conflicts and their determinants come from the Database of Political Institutions (2012) and the UCDP / PRIO Armed Conflict Dataset (2009). Control variables: social infrastructure which is based on the political system (dictatorial, military or democratic) and trade 
openness ( 1 and inflation come from the databases of the NYU Global Development Network Growth. The human development indicator taken from WDI and UNDP databases Physical and human capital and Physical capital stock are taken from NYU Global Development Network Growth database- based on WDI, human capital index is taken from Penn World Trade, version 8.1 (Feenstra et al. 2015).

\section{Section three: estimation results}

Two main results emerge from the estimate. The first result suggests that conflicts have a negative impact on growth because they depress activity (Venugopal, 2018). Economic growth creates new social divides that increase the opportunity for conflict and inhibit any growth process in the short and long term. The second result is that the elasticity of short-term conflicts in these countries seems to be able to project fragile economies more quickly onto trajectories that lead them less towards their level of long-term equilibrium growth (tables one and two on pages 11 and twelve).

3.1. Conflicts have negative impacts on economic growth: channels for financing war and increasing the cost of capital Model one. "Social divide and conflicts" are globally significant and contribute negatively to long-term economic growth. This negative impact is attributable both to the increase in military expenditure and to the fall in budgetary revenues following an increase in real interest rates which depress activity (Barro, 1987) and also in view of the increase in costs of conflict-related business practices (Knight et al. 1996). The long-run elasticity of conflicts with respect to growth is 0.03 points for the entire panel. Thus, any one point increase in an occurrence of conflict induces a $3 \%$ drop in growth in per capita GDP for the entire panel. Likewise, the effect of minor conflicts with instrumentation of conflict appears to be more pronounced in the long run than without it on growth. In the literature two theses clash. Civil war is the daily life of these countries and macroeconomic stability the exception. These results are mainly observed when the endogeneity due to reverse causality is taken into account. This phenomenon of endogeneity is taken into account through the instrumentation of the "conflict" in the estimation of the model one and two specified. We observe that the long-term elasticity coefficients of conflicts with respect to economic growth are negative. Thus, any increase of one point in the intensity of conflicts as a percentage of GDP per capita induces losses of -0.49 and -0.14 point in activity for the entire panel.

Conversely, an accumulation of human capital by one point over a long period improves GDP growth by $5 \%$, which puts the debate on endogenous growth on the agenda (Wang and Liu, 2016) while the elasticity of physical capital is less important on economic growth compared to the index of human capital. This updates the old debate about a delay due to the more or less lack of physical and human capital orchestrated by developmental inequalities and dysfunctional labour market (Psacharopoulos et al. 2018). Then, an adjustment of military spending on the part of the States seems to have a significant and negative contribution to growth with a longterm elasticity coefficient of -0.91 point taking into account the fact that during this period, the interest rate higher and imports depress activity and growth (Barro, 1987).

The elasticity of the non-significant convergence coefficient of around 0.03 point shows that the estimated speed of adjustment to permanent shocks is very important and considerable for incentives to activity. Thus, the sensitivity of the conflicts in these countries seems to be able to project more quickly the fragile economies of Sub-Saharan Africa on trajectories which lead them less towards their level of long-term equilibrium growth. This seems to explain the feedback effect of economic growth with respect to its equilibrium value. This negative impact may be attributable to the huge expenditure due to the financing of the war which increases the budget deficit and increases the debt of the country which depresses the activity. The one point increase in inequality as a percentage of GDP leads to a decrease of 0.32 percentage point of growth in the whole sample (Fosu, 2015). This maintains a high level of initial inequality and leads to conflicts and then to country instability as to why Africa is the second most unequal continent in the world, after Latin America (Devarajan, 2013). Conversely, an additional opening unit leads to an appreciation of GDP of an order greater than $1.09 \%$ for the countries concerned. Thus, countries with greater trade openness have relatively greater economic growth compared to less open countries (Asiedu, 2003). The World Bank (1993) shows that more openness attracts foreign direct investment flows, strengthens innovation and high productivity growth activities.

Table 1 Impacts of the social divide and conflicts on the economic growth of a few fragile countries in Sub-Saharan Africa: a "Pooled Mean Group" regression

\begin{tabular}{|l|l|l|}
\hline \multicolumn{2}{|l|}{ Fragile Countries of Saharan Africa } \\
\hline Dependent variable: economic growth & Model 1. Intensities of conflicts \\
\hline Long term Coefficients & With conflicts instrumentation & Without conflicts instrumentation \\
\hline Minor Conflicts & $-0,49^{* * *}$ & $-1,20^{* *}$ \\
& $(0,13)$ & $(0,49)$ \\
\hline Major Conflicts & $-0,14^{* * *}$ & $-1,08^{* * *}$ \\
& $(0,04)$ & $(0,29)$ \\
\hline Stock of physical capital & $0,007 \mathrm{~ns}$ & $-0,24 \mathrm{~ns}$ \\
& $(0,01)$ & $(0,15)$ \\
\hline Stock of human capital & $5,00^{* * *}$ & $3,14 * * *$ \\
& $(1,05)$ & $(0,77)$ \\
\hline Military expenditure & $-0,94^{* * *}$ & $0,64 \mathrm{~ns}$ \\
& $(0,24)$ & $(0,40)$ \\
\hline Trade openness & $-0,96^{* * *}$ & $0,13 \mathrm{~ns}$ \\
& $(0,11)$ & $(0,17)$ \\
\hline Social divide & $0,39^{* *}$ & $0,27 \mathrm{~ns}$ \\
& $(0,14)$ & $(0,26)$ \\
\hline
\end{tabular}




\begin{tabular}{|c|c|c|}
\hline Convergence Coefficients & $\begin{array}{l}-0,33 * * * \\
(0,08)\end{array}$ & $\begin{array}{l}-0,03 \mathrm{~ns} \\
(0,04)\end{array}$ \\
\hline \multicolumn{3}{|l|}{ Short term Coefficients } \\
\hline Minor Conflicts & $\begin{array}{l}-0,32 \mathrm{~ns} \\
(0,01)\end{array}$ & $\begin{array}{l}0,02 \mathrm{~ns} \\
(0.04)\end{array}$ \\
\hline Major Conflicts & $\begin{array}{l}-0,007 \mathrm{~ns} \\
(0,007)\end{array}$ & $\begin{array}{l}0,03 \mathrm{~ns} \\
(0,03)\end{array}$ \\
\hline Stock of physical capital & $\begin{array}{l}-0,10 \mathrm{~ns} \\
(0,13)\end{array}$ & $\begin{array}{l}-0,11 \mathrm{~ns} \\
(0,14)\end{array}$ \\
\hline Stock of human capital & $\begin{array}{l}7,93 \mathrm{~ns} \\
(8,93)\end{array}$ & $\begin{array}{l}-5,57 \mathrm{~ns} \\
(6,36)\end{array}$ \\
\hline Military expenditure & $\begin{array}{l}-0,03 \mathrm{~ns} \\
(0,02)\end{array}$ & $\begin{array}{l}-0,04 \mathrm{~ns} \\
(0,03)\end{array}$ \\
\hline Trade openness & $\begin{array}{l}-0,08 * * \\
(0,39)\end{array}$ & $\begin{array}{l}-0,06 \mathrm{~ns} \\
(0,04)\end{array}$ \\
\hline Social divide & $\begin{array}{l}0,02 \mathrm{~ns} \\
(0,03)\end{array}$ & $\begin{array}{l}-0,01 \mathrm{~ns} \\
(0,02)\end{array}$ \\
\hline Number of countries & 6 & 6 \\
\hline Number of observations & 168 & 168 \\
\hline \multicolumn{3}{|c|}{ Standard Deviations are in brackets. } \\
\hline
\end{tabular}

Source: author

\subsection{Are past inequalities the melting pot of present inequalities or do they reduce growth?}

Model two. The effect of past inequalities on present inequalities in economic growth remains contentious and controversial in the economic literature to the extent that opinions differ as to the nature of this link (Fosu, 2015). Some advocate an inverse relationship, and others, on the other hand, see it more as a selfsustaining link that consolidates inequalities and fuel new social tensions that are a source of instability and growth (Dubois, 2005). The estimates obtained after instrumentation of the conflict and growth variables raise a general outcry even with our main results concerning the political system control variable. Indeed, good policies and strong institutions improve openness and strengthen the growth and competitiveness of economies (Adam Smith and David Ricardo). With an increase in growth by one more point, there is an increase and multiplication of inequalities of the order of 0.09 points. On the other hand, any increase of one point in a minor conflict reduces inequalities by an order of -0.1 point while an additional unit of a major conflict reinforces inequalities of the same order. This erodes the growth and annihilates the development of these countries and reinforces the extreme poverty and the vulnerability to poverty over a longer period of time through the prism of an increase in poverty rates and strong inequalities in the distribution of wealth (Stiglitz, 2008). On the other hand, increasing growth by one point has positive and significant effects on reducing inequalities of the order of -0.09 points. This result is counterintuitive because minor conflicts act more negatively on growth than major conflicts. However, the relationship between the occurrence of conflicts and economic growth is ambiguous in most developing countries which form the hard core of Sub-Saharan African (SSA) countries due to structural constraints and budget deficits.

Table 2. Effect of economic growth and conflict on the social divide in fragile countries, 1980-2008, Two-step generalized method of moments

\section{With instrumentation of conflicts and growth}

\begin{tabular}{|l|l|}
\hline $\begin{array}{l}\text { Dependent Variable : Social } \\
\text { divide }\end{array}$ & Two-step GMM estimators \\
\hline Social divide, $\mathrm{t}-1$ & $\begin{array}{c}0.4582 * * * \\
(0.0912)\end{array}$ \\
\hline Minor conflicts & $-0,1041^{*}$ \\
& $(0.0769)$ \\
\hline Major conflicts & $0.0054^{*}$ \\
& $(0.00008)$ \\
\hline Political system & $-0.0419 * *$ \\
& $(0.2908)$ \\
\hline Economic growth & $-0.0904 * * *$ \\
& $(0.02395)$ \\
\hline Trade openness & $-0.0966 * * *$ \\
& $(0.0209)$ \\
\hline Number of countries & 6 \\
\hline Number of observations & 162 \\
\hline Standard deviations are in parentheses \\
\hline$* * * \mathrm{p}<0.01, * * \mathrm{p}<0.05, * \mathrm{p}<0,1$. \\
\hline
\end{tabular}

\section{Source: Author}

In contrast, in the absence of conflicts instrumentation and growth, conflict, be it minor or major contributes in the reduction of social inequalities. This seems paradoxical because conflict situations undermine social cohesion and undermine social balance. This cause investors to be reluctant, depresses the activity leading to growth. The convergence hypothesis is also supported by the negative and significant coefficient at $1 \%$ level of GDP per capita growth. However, this means that the growth lagged by one period contributes positively and significantly to the reduction of inequalities over the period of the study Gupta et al. (2004).

Table 2.1 Effect of economic growth and conflict on the social divide in fragile countries, 1980-2008, Two-step generalized method of moments

\begin{tabular}{|l|c|}
\hline Without instrumentation of conflicts and growth \\
\hline $\begin{array}{l}\text { Dependent Variable : Social } \\
\text { divide }\end{array}$ & Two-step GMM estimators \\
\hline Social divide, t-1 & $0.4594^{* * *}$ \\
\hline
\end{tabular}




\begin{tabular}{|l|l|}
\hline & $(0.0886)$ \\
\hline Minor conflicts & $-0.0579^{*}$ \\
& $(0.0935)$ \\
\hline Major conflicts & $-0.1409^{*}$ \\
& $(0.1346)$ \\
\hline Political system & $-0.1011^{*}$ \\
& $(0.0878)$ \\
\hline Economic growth & $-0.0907^{* * *}$ \\
& $(0.0225)$ \\
\hline Trade openness & $-0.0947^{* * *}$ \\
& $(0.0199)$ \\
\hline Number of countries & 6 \\
\hline Number of observations & 162 \\
\hline Standard deviations are in parentheses \\
\hline$* * * p<0.01, * * \mathrm{p}<0.05, \mathrm{p}<0,1$. \\
\hline
\end{tabular}

Source: Author

\section{Conclusion}

Do the social divide and the occurrence of conflicts affect the economic growth of fragile Sub-Saharan Africa countries? This question takes on particular intensity at a time when economic growth constitutes a major objective for economic development. While the social divide and conflicts result from the entanglement of several factors (cultural, social, political, military, geopolitical) each having their own temporality, the effects of which are detrimental not only to the stability of countries but also to the attractiveness of FDI source of growth and productivity. The article is an empirical analysis of the relationship between social divide, the occurrence of conflict and economic growth. The overall negative effect of inequality and conflict on economic performance is confirmed by a growing body of literature. Compared to the existing literature and especially according to Collier (2009), countries whose growth depends on human and physical capital and high transaction costs are the most vulnerable to conflicts and are prone to impoverishing growth. By therefore using ARDL models from the econometric point of view to study the link between conflicts and growth and the Generalized Moments Method (GMM) to solve endogeneity problems including that of the social divide on growth, the results indicate that any one point increase in a conflict occurrence induces a 3\% drop in growth in GDP per capita across the entire panel. Then, the social divide and the conflicts annihilate the economic growth and vice versa. The logical postulates advanced in this article were based on verifiable and justifiable stylized facts (Psacharopoulos et al. 2018). We have also similarly demonstrated that, consistent with the underlying literature, high inequalities reinforce social polarization and depress activity. Verporten (2013) suggests that it is difficult to have a clear opinion on the impact of social divide and conflict on economic growth. In our opinion, the opacity of African regimes and open corrupt practices generate new social fractures and the opportunity for conflict. The additional observation is that the decline in growth resulting from the increase in the social divide and conflicts is totally absorbed by the increase in military spending and by poor macroeconomic policy (Venugopal, 2018). This result is intuitive in that the high level of resources devoted to military spending and the embezzlement of public funds orchestrated by dictatorial political systems are often proposed to systematically explain the constraints on supply. Three recommendations emerge from this article: first, strengthen institutions by cleaning up the institutional framework; secondly, to modify the patterns of economic policy by admitting the positive adjustments and by putting in place the corrective elements which modify the instrumental variables according to whether the cause is cyclical or structural; and thirdly, the poor performance in terms of growth cannot be blamed on conflicts whose exacerbation would be the "cause" but must lead decision-makers to reflect on the structural causes.

\section{Data Availability}

The data are taken from the sources: the real exchange rate (WDI) of the World Bank; physical capital stock, trade openness (the total share of exports and imports in GDP) and inflation are taken from the NYU Global Development Network Growth database - based on WDI; the human capital index is taken from Penn World Trade, version 8.1 (Feenstra et al. 2015), and ${ }^{2}$ military spending, conflicts (occurrence and intensity) and their determinants come from the Database of Political Institutions (2012) and UCDP / PRIO Armed Conflict Dataset (2009)

\section{Conflicts of Interest}

The author declares that there is no conflict of interest regarding the publication of this paper

\section{Funding Statement}

The research and publication of this article was funded by the presidential bonus and the support of a sister

\section{Acknowledgments}

We say, in a special thank you, to the late Professor NEMB Pierre Samuel for his assistance and reading this manuscript. To Professor BAYE MENJO Francis for econometric tests.

\section{Bibliographical References}

[1] ABADIE A. et GARDEAZABAL J. (2003), "The Economic Costs of Conflict: A Case Study of the Basque Country". American Economic Review vol 93 n¹, 113 32.

[2] ANYANWU, J. C. (2002), "Economic and Political Causes of Civil Wars in Africa: some Econometric Results", Economic Research Papers, BAD, n ${ }^{\circ} 73$, Abidjan.

[3] ARELLANO M. et BOND S. (1991), "Some tests of specication for panel data: Monte Carlo evidence and an application to employment equations". Review of Economic Studies 58, 277-297.

[4] BARRO R. J. et LEE J.W. (2012), "A New Data Set of Educational Attainment in the World: 1950-2010", Updated Version. Available at http://www.barrolee.com.

[5] BASSANINI A. et SCARPETTA S. (2001), "Does Human Capital Matter for Growth in OECD Countries? Evidence from Pooled Mean-Group Estimates". OECD Economics Department, Working Paper ${ }^{\circ} 282$

[6] BAYRAMZADEH K. (2015), "Failed states and transnational terrorism". Review of the Faculty of Law of the University of Liège BLATTMAN C et MIGUEL E. (2010), "Civil War". Journal of Economic Literature vol $48 n^{\circ} 1,3-57$. 
[7] BODEA C. et ELBADAWI I A. (2008), "Political Violence and Economic Growth". World Bank Policy Research Working Paper 4692.

[8] CERRA V. et SAXENA S.C(2008), "Growth Dynamics: The Myth of Economic Recovery". American Economic Review, vol $98 \mathrm{n}^{\circ} 1,439-57$.

[9] CHAN, L, RUWANPURA, K. N. ET BROWN, B. (2019), "Environmental Neglect: Other casualties of post-war infrastructure development". Geoforum., ${ }^{\circ} 105$, 63-66.

[10] CHEN W. Y., HO C.Y, PHOON M. C., TAN, C. F. et TAN X. J. (2016), "Myths About Education and Economic Growth in Malaysia": A Mediation Analysis, University of Tunku Abdul Rahman.)

[11] COCHRANE S.H. (1979), "Fertility and Education: What Does we Really Know?" University Press COLLIER P. (2009), "Post-conflict Recovery: How Should Strategies Be Distinctive?" Journal of African Economies 18, AERC Supplement 1, 99-131

[12] DE GROOT O. (2010), "The Spill-Over Effects of Conflict on Economic Growth in Neighboring Countries in Africa". forthcoming in Defence and Peace Economics.

[13] DEININGER K and SQUIRE L. (1997), "A New Data Set Measuring Income Inequality". World Bank Economic Review 10, September: 565-591

[14] DEVARAJAN S. (2013), "Africa's Statistical Tragedy". Review of Income and Wealth, ${ }^{\circ}$ 59, S9-S15

[15] DUBOIS J.L. (2005), "Can strategic frameworks for combating poverty integrate the issue of development sustainability? What sustainable development for developing countries? GEMDEV Notebook No. 30, November

[16] FEENSTRA R. C., INKLAAR R. et TIMMER M. P. (2015), "The Next Generation of the Penn World Table forthcoming" in American Economic Review, available for download at www.ggdc.net/pwt

[17] FIELDING D. (2004), "How Does Violent Conflict Affect Investment Location Decisions? Evidence from Israel during the Intifada”. Journal of Peace Research vol $41 n^{\circ} 4,465-84$

[18] GODERIS B. et MALONE S W. (2009), "Natural Resource Booms and Inequality: Theory and Evidence". Ox Carre Research Paper, August

[19] GROSSMAN F and HELMA E. (1991), "A General Equilibrium Model of Insurrections", American Economic Review, 81(4), 912-21

[20] GUPTA S. CLEMENTS B. BHATTACHARYA R. et CHAKRAVARTI S. (2004), "Fiscal Consequences of Armed Conflict and Terrorism in Low- and MiddleIncome Countries". European Journal of Political Economy n ${ }^{\circ} 20,403-21$

[21] HUGON, P. (2003), "Armed conflicts in Africa: contributions, myths et limits of economic analysis", Tiers Monde, $\mathrm{n}^{\circ}$ 176, October December.

[22] HUGON, P. (2006), "Armed Conflict in Africa: the role of economic factors", The European Journal of Development Research, Franck Cass publishers.
[23] IMAI K. WEINSTEIN J. (2000), "Measuring the Economic Impact of Civil War". CID Working Paper 51, Harvard University.

[24] JEAN, F. et J.-C. RUFFIN (1996), "Economics of civil wars", Hachette, Paris

[25] KNIGHT M., LOAYZA N. et VILLANUEAVA D. (1996), "The Peace Dividend: Military Spending Cuts and Economic Growth". IMF Staff Papers, vol $43 n^{\circ} 1,1-$ 37

[26] KOUBI V. (2005), "War and Economic Performance". Journal of Peace Research vol $42 \mathrm{n}^{\circ} 1,67-82$

[27] Lin J Y. (2015), "The Washington Consensus Revisited A New Structural Economics Perspective", Journal of Economic Policy Reform, vol 18 n², 96-113.

[28] LOPEZ H. et WODON Q. (2005), "The Economic Impact of Armed Conflict in Rwanda". Journal of African Economies vol $14 n^{\circ} 4,586-602$

[29] MANKIW G. D. ROMER, et WEIL D. (1992), “A Contribution to the Empirics of Economic Growth", Quarterly Journal of Economics, 407-438

[30] MILANOVIC B. (2005), "Worlds Apart: Measuring International and Global Inequality", Princeton University Press PAUGAM S. (2014), "Social disqualification". Essay of the new poverty; Paris, PUF, 8th édition, coll.

[31] PAUGAM S. (2016), "Poverty and vulnerability in times of crisis". French Note books; n ${ }^{\circ} 39$ PERROUX F. (1991), "The Economy of the 20th Century", PUF, 3rd ed PESARAN M.H., SHIN, Y et SMITH R.P. (1999), "Pooled mean group estimation of dynamic heterogeneous panels", Journal of the American Statistical Association 94, 79-113.

[32] PSACHAROPOULOS G. et PATRINOS H.A. (2018), "Return to Investment in Education" A decennial Review of the global literature, Education Economics, vol 26 $\mathrm{n}^{\circ} 5,445-458$

[33] STIGLITZ J. E. et BILMES J L. (2008), "The Three Trillion Dollar War: The True Cost of the Iraq Conflict", Londres, W.W Norton and Company

[34] SVENSSON J. (1998), "Investment, Property Rights and Political Stability: Theory and Evidence". European Economic Review n²42, 1317-41.

[35] VENUGOPAL, R. (2018), "Nationalism, Development and ethnic conflict in Sri Lanka". Cambridge: Cambridge University Press.

[36] VERPOORTEN M. (2009), "Household Coping in War and Peacetime: Cattle Sales in Rwanda, 1991-2001". Journal of Development Economics vol $88 n^{\circ} 1,67-86$.

[37] WANG, Y. and Liu S.S. (2016), “Education, Human Capital and Economic Growth: Empirical Research on 55 Countries and Regions (1960-2009)', Theoretical Economics Letters, 6, pp. 347-355

[38] YAMBEN M. F. H. et TENLEP A. M. (2021), "Conflicts Do They Affect the Overall Competitiveness of Sub-Saharan African Fragile Countries? An Approach of the Pooled Mean-Group" International Journal of Social Science and Economics Invention, Volume 07, Issue 02 February, pp. 27-35. https//doi: org/10.23958/ijsseivol_i02/262 